\title{
ChemPlusChem
}

Supporting Information

\section{V-Shaped Methylpyrimidinium Chromophores for Nonlinear Optics}

Sylvain Achelle, ${ }^{*}$ Egor V. Verbitskiy, Michaela Fecková, Filip Bureš, ${ }^{*}$ Alberto Barsella, and Françoise Robin-le Guen 


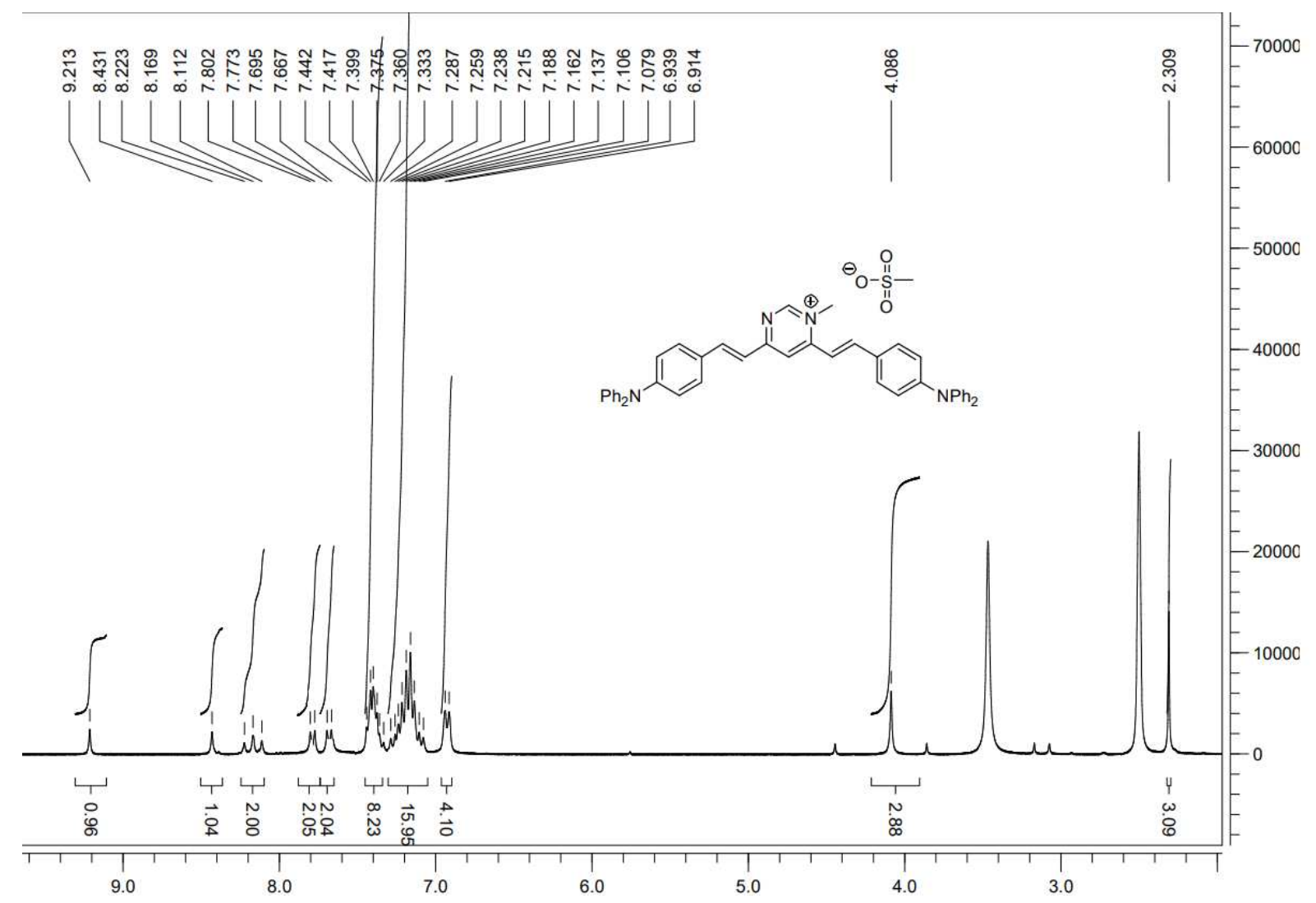

Figure $\mathbf{S 1}:{ }^{1} \mathrm{H}$ NMR spectrum $(300 \mathrm{MHz})$ of 1 in DMSO- $d_{6}$

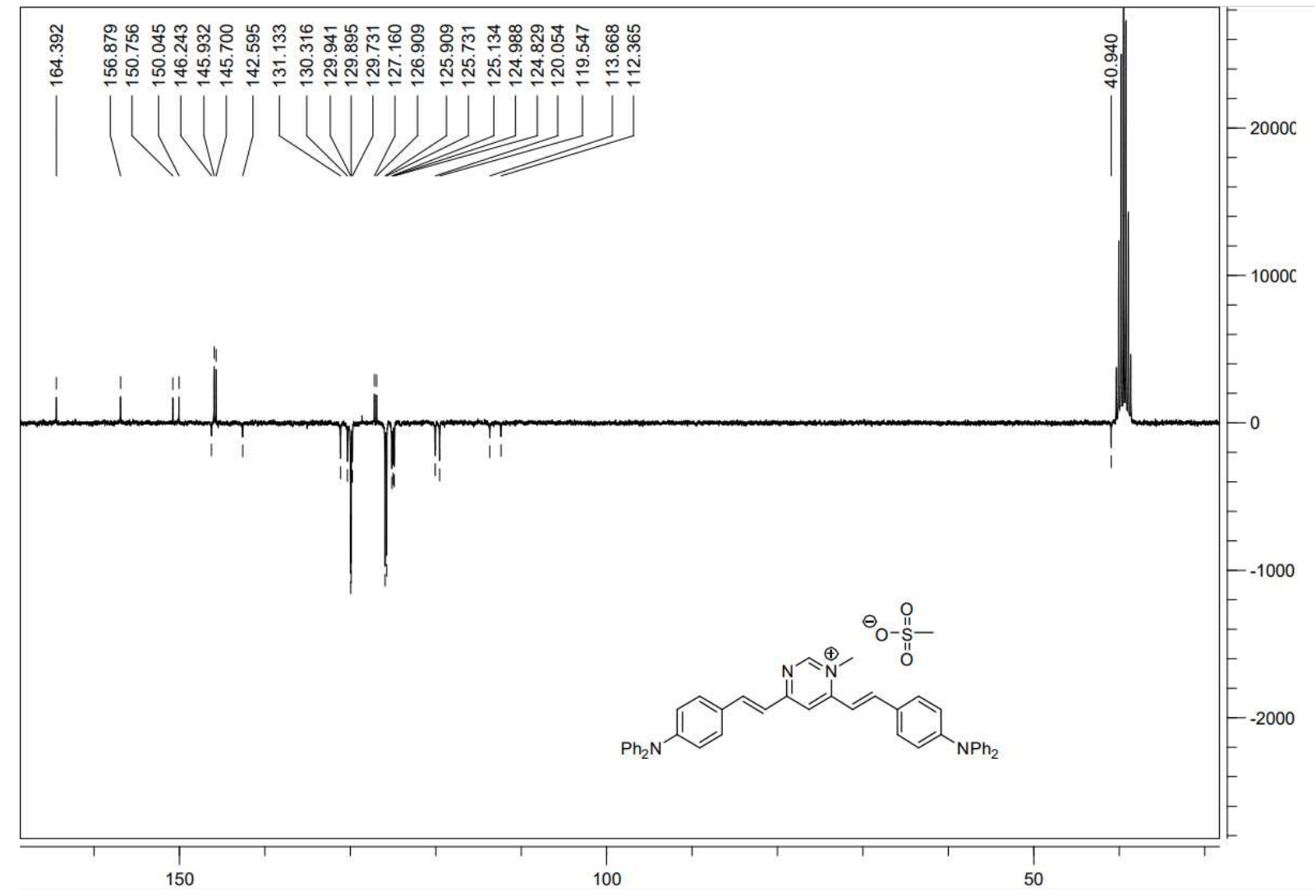

Figure S2: ${ }^{13} \mathrm{C}$ NMR spectrum $(75 \mathrm{MHz})$ of $\mathbf{1}$ in DMSO- $d_{6}$ 


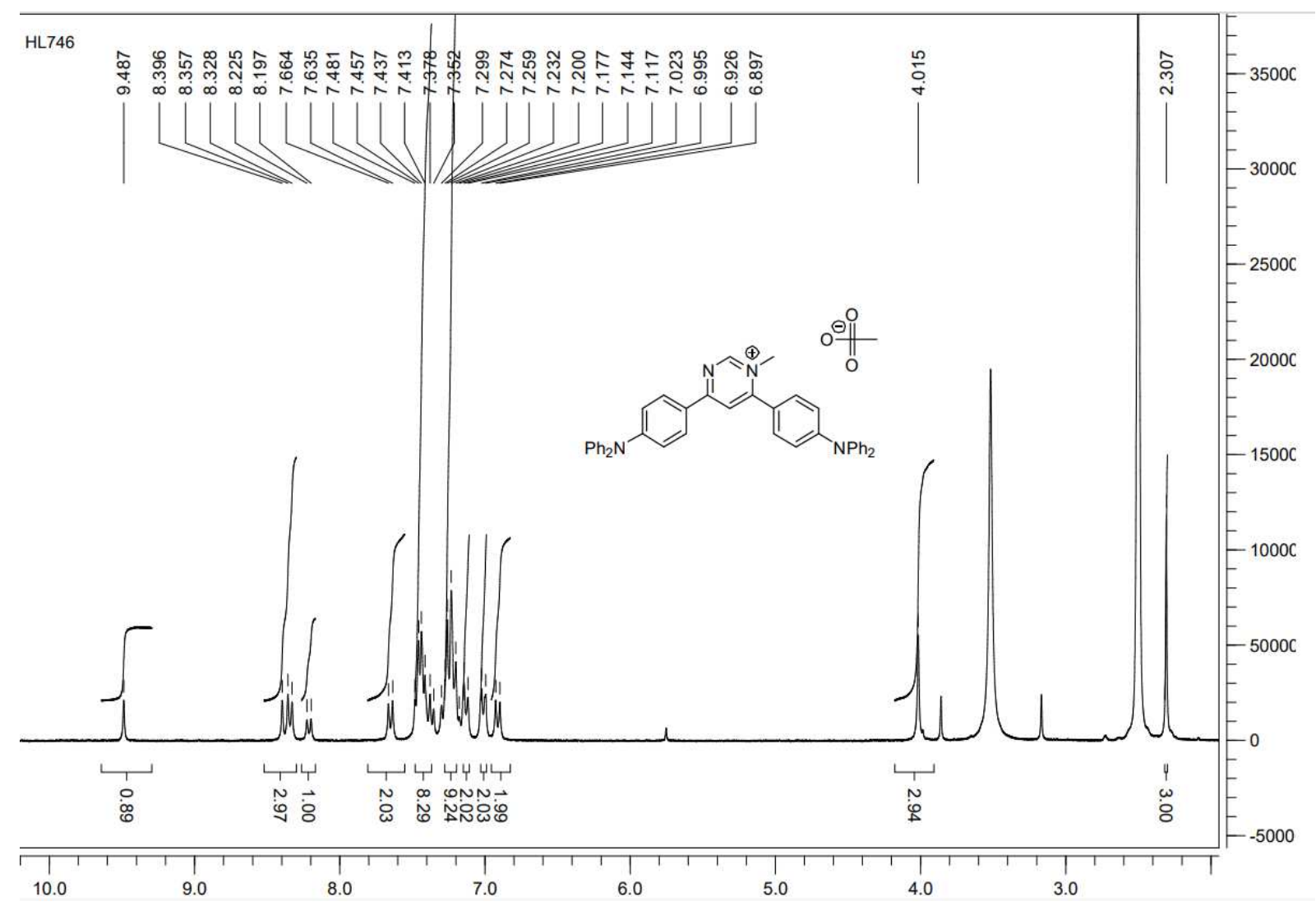

Figure S3 : ${ }^{1} \mathrm{H}$ NMR spectrum $(300 \mathrm{MHz})$ of 2 in DMSO- $d_{6}$

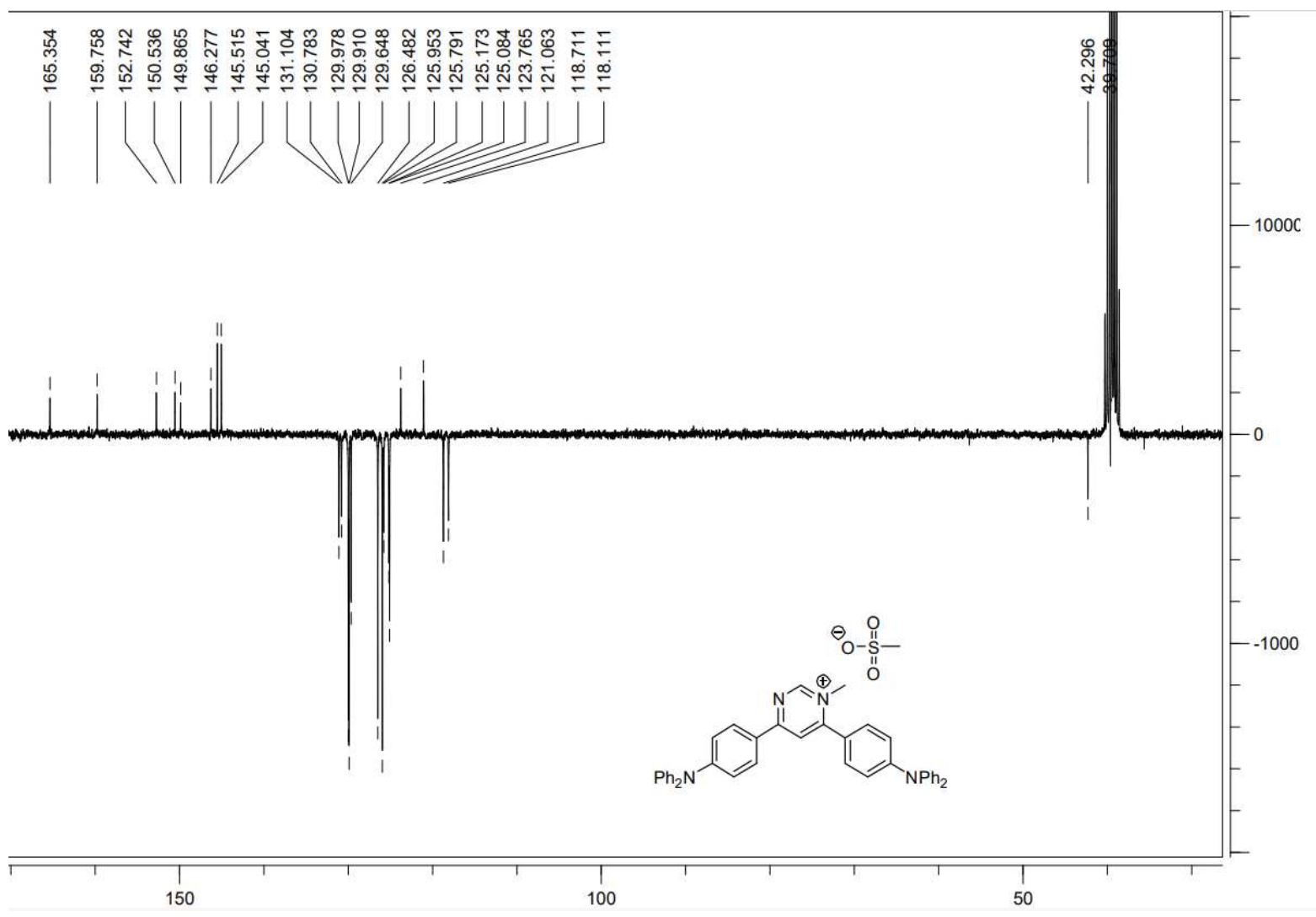

Figure S4: ${ }^{13} \mathrm{C}$ NMR spectrum $(75 \mathrm{MHz})$ of $\mathbf{2}$ in DMSO- $d_{6}$ 


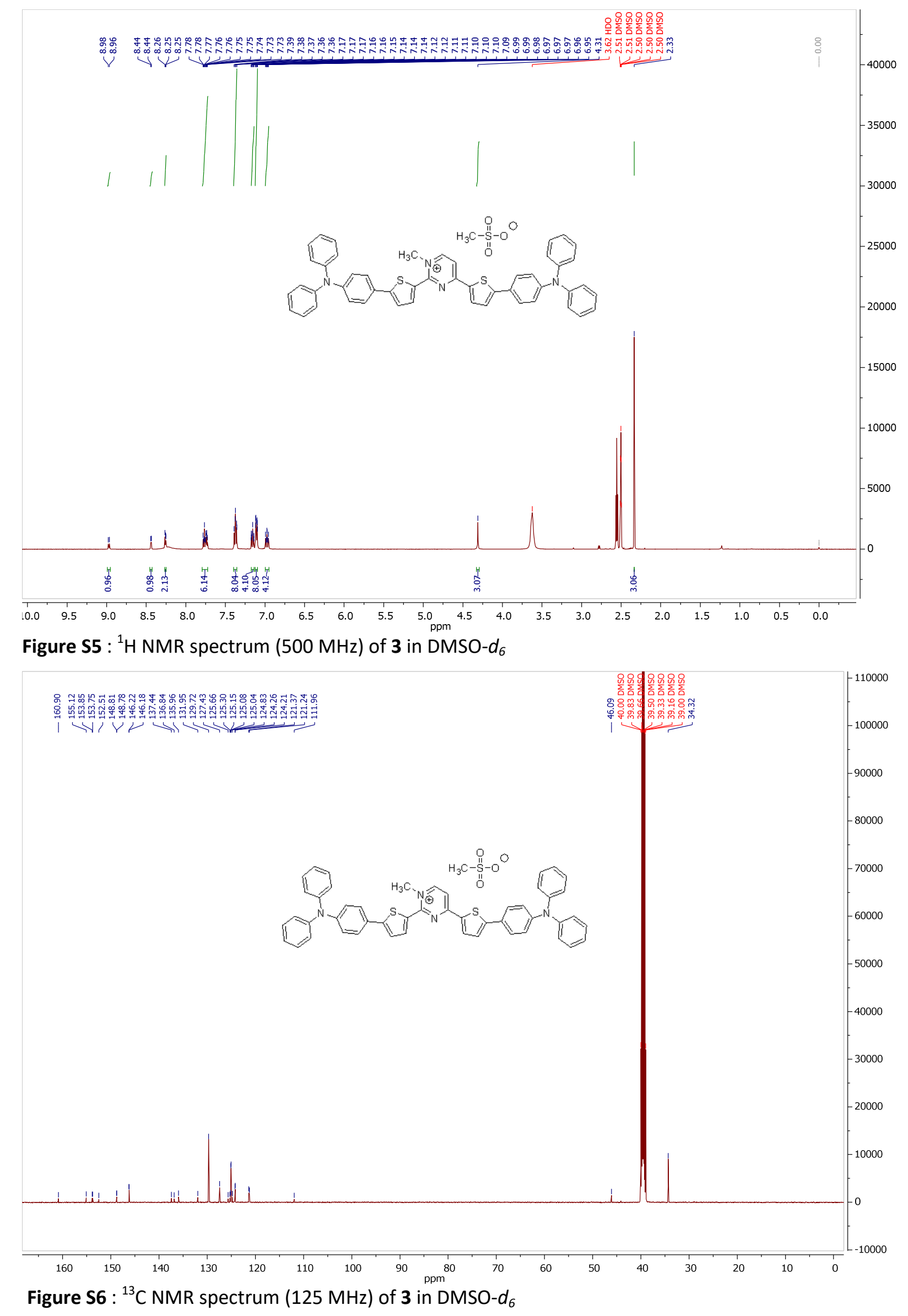




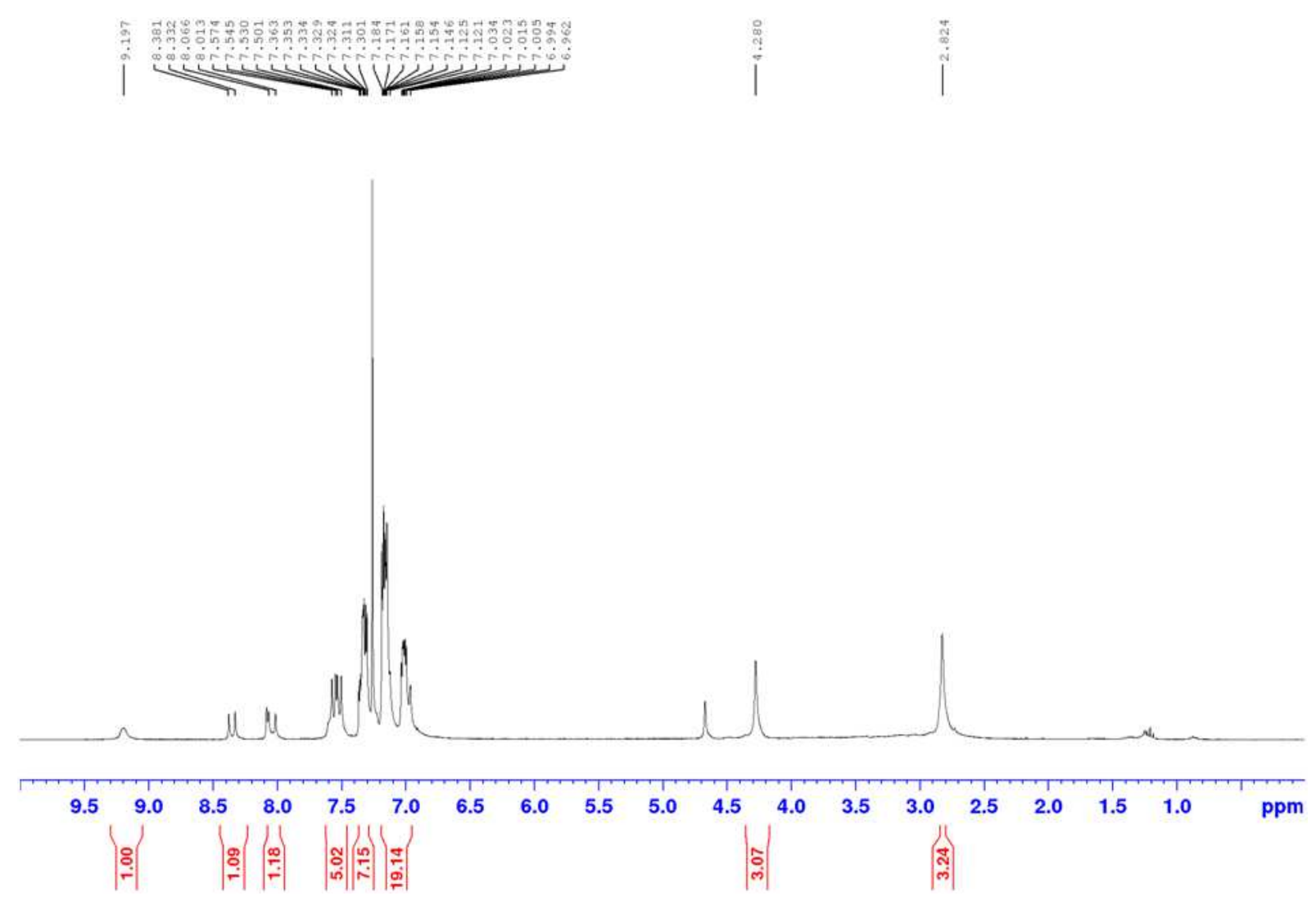

Figure S7 : ${ }^{1} \mathrm{H}$ NMR spectrum $(300 \mathrm{MHz})$ of $\mathbf{4}$ in DMSO- $d_{6}$

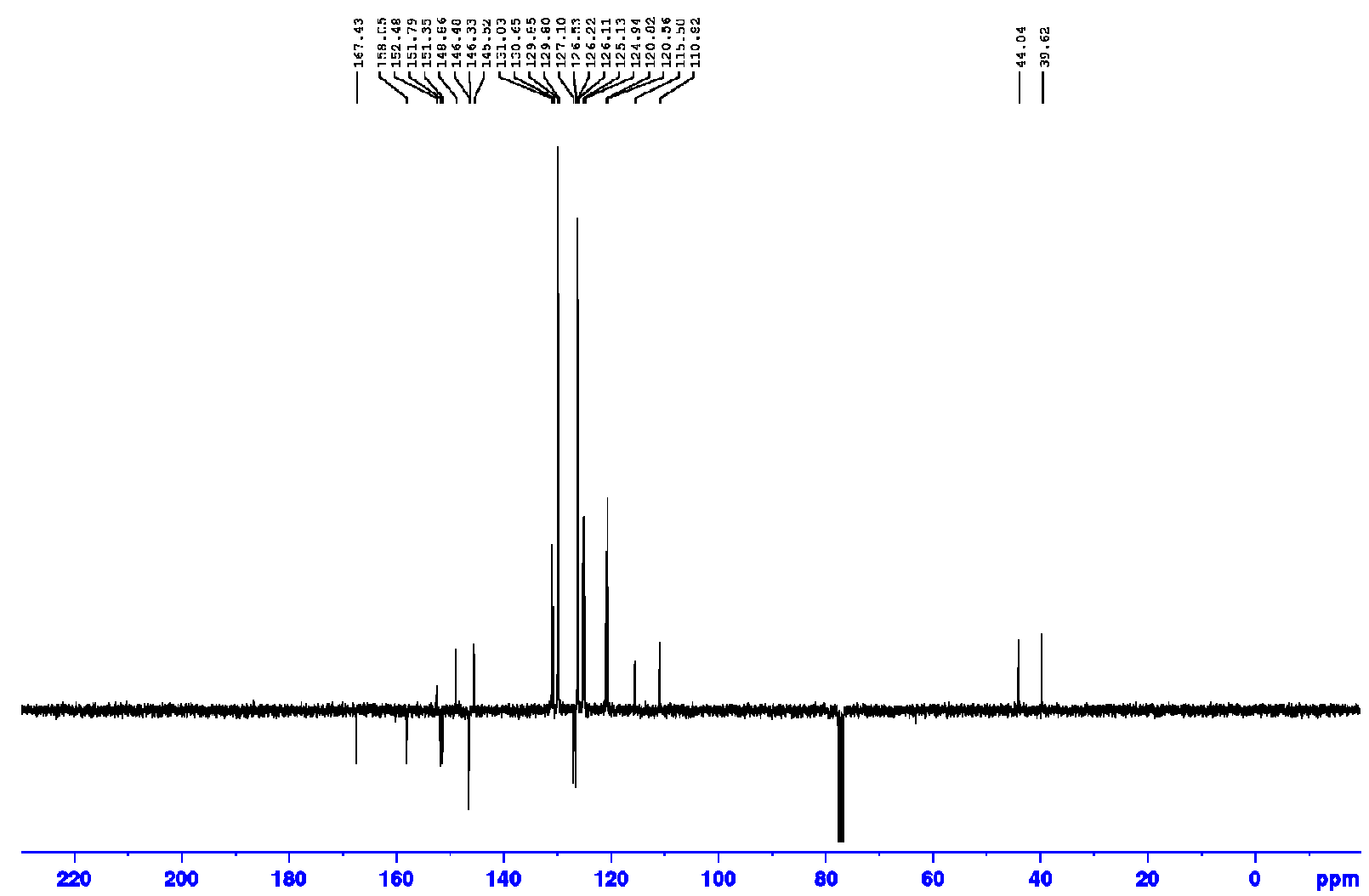

Figure S8: ${ }^{13} \mathrm{C}$ NMR spectrum $(75 \mathrm{MHz})$ of 4 in DMSO- $d_{6}$ 

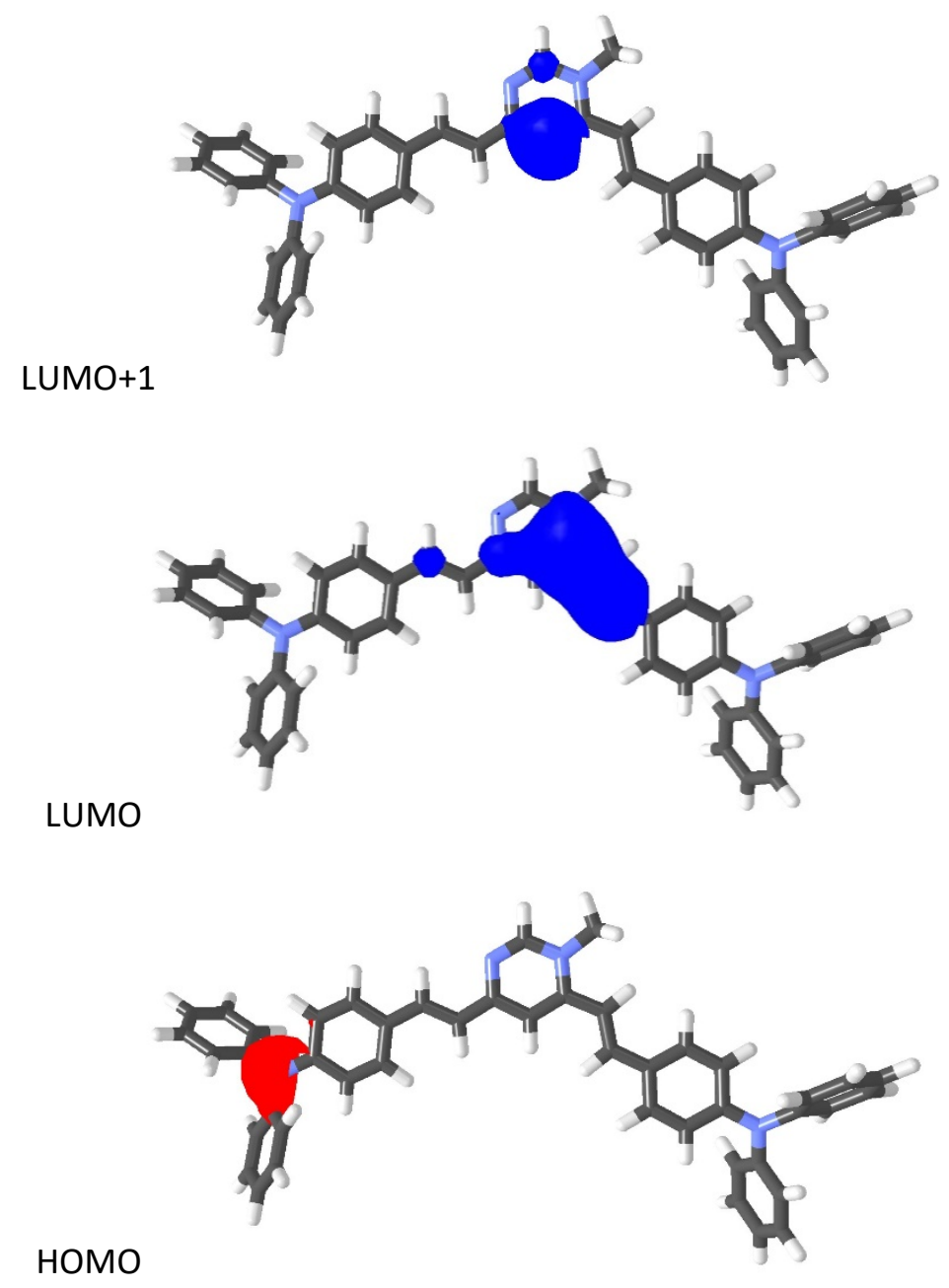

HOMO

HOMO-1

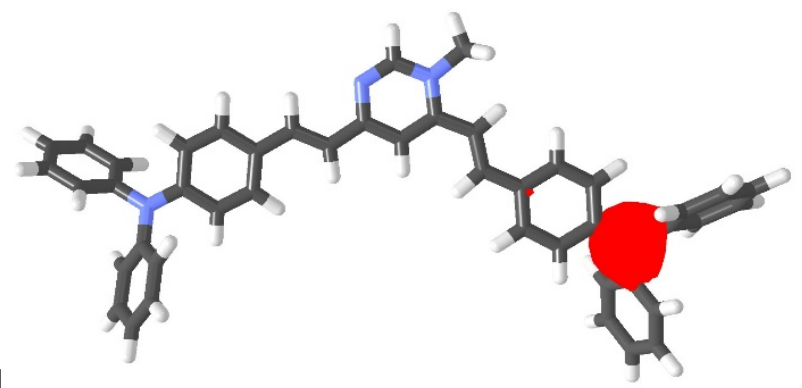

Figure S9: $\mathrm{HOMO}(-1)$ and $\mathrm{LUMO}(+1)$ localizations in chromophore 1 shown in red and blue, respectively. 

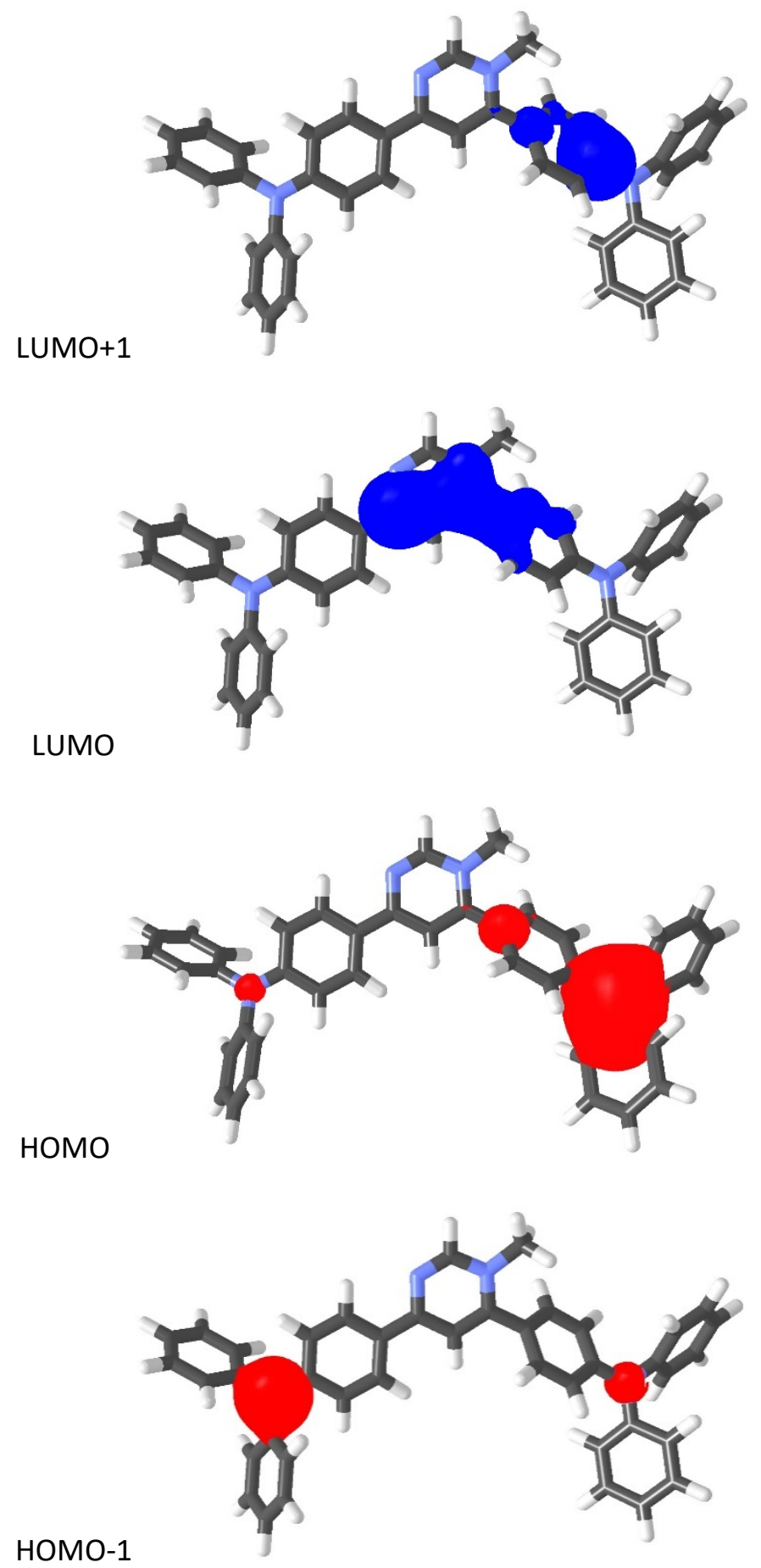

Figure S10: $\mathrm{HOMO}(-1)$ and $\operatorname{LUMO}(+1)$ localizations in chromophore 2 shown in red and blue, respectively. 

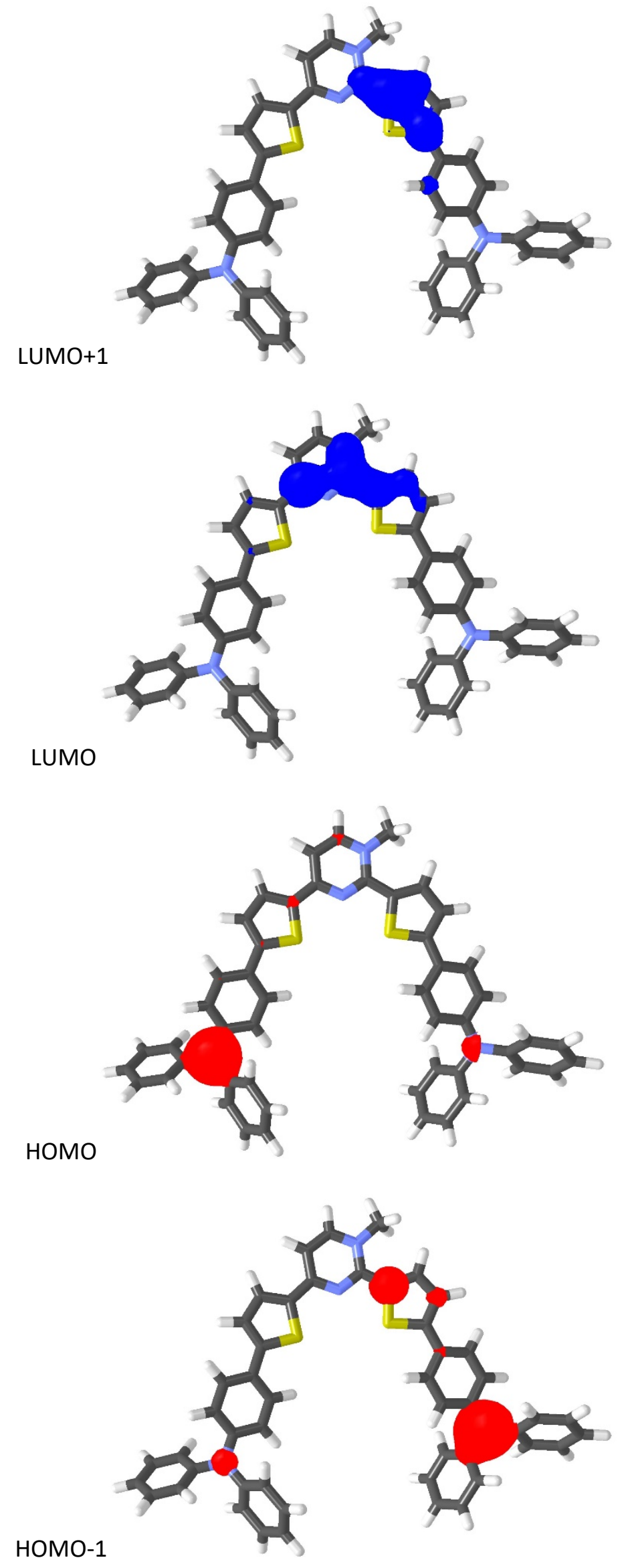

Figure S11: $\mathrm{HOMO}(-1)$ and $\mathrm{LUMO}(+1)$ localizations in chromophore 3 shown in red and blue, respectively. 

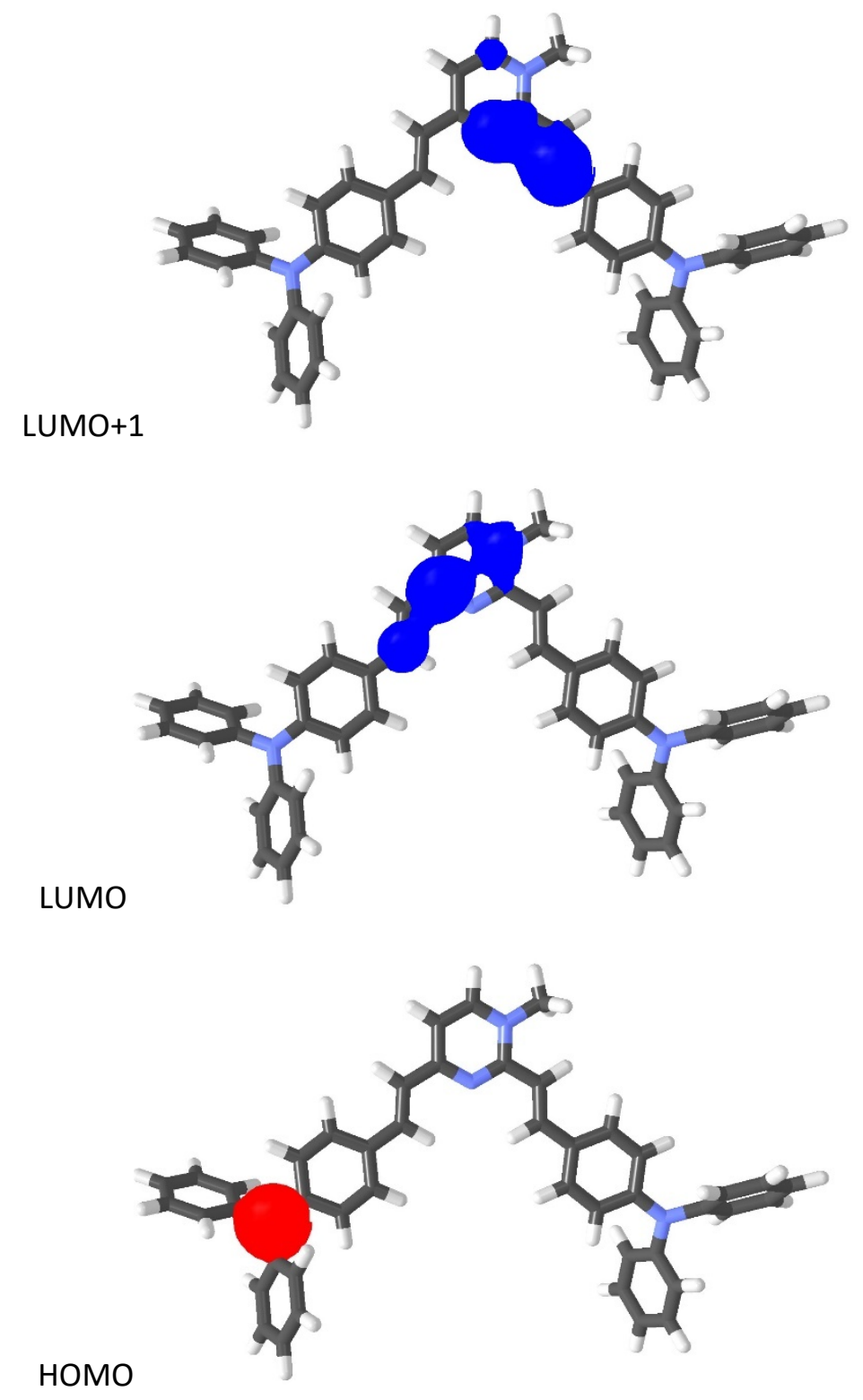

HOMO-1

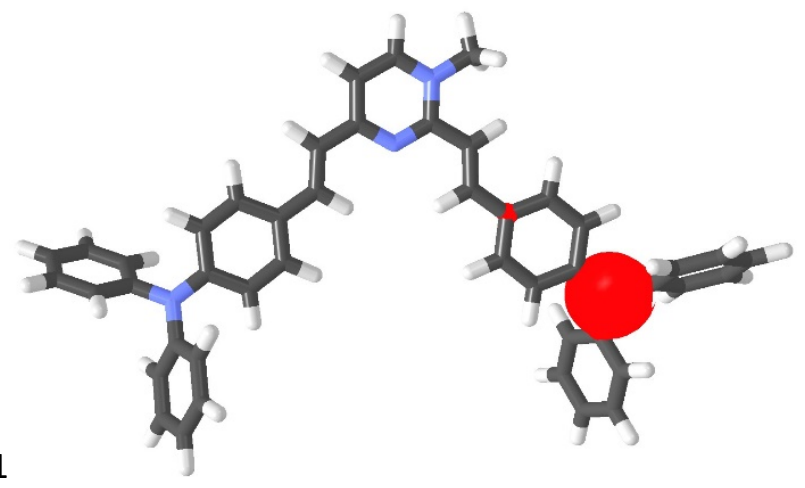

Figure S12: $\mathrm{HOMO}(-1)$ and $\operatorname{LUMO}(+1)$ localizations in chromophore 4 shown in red and blue, respectively. 


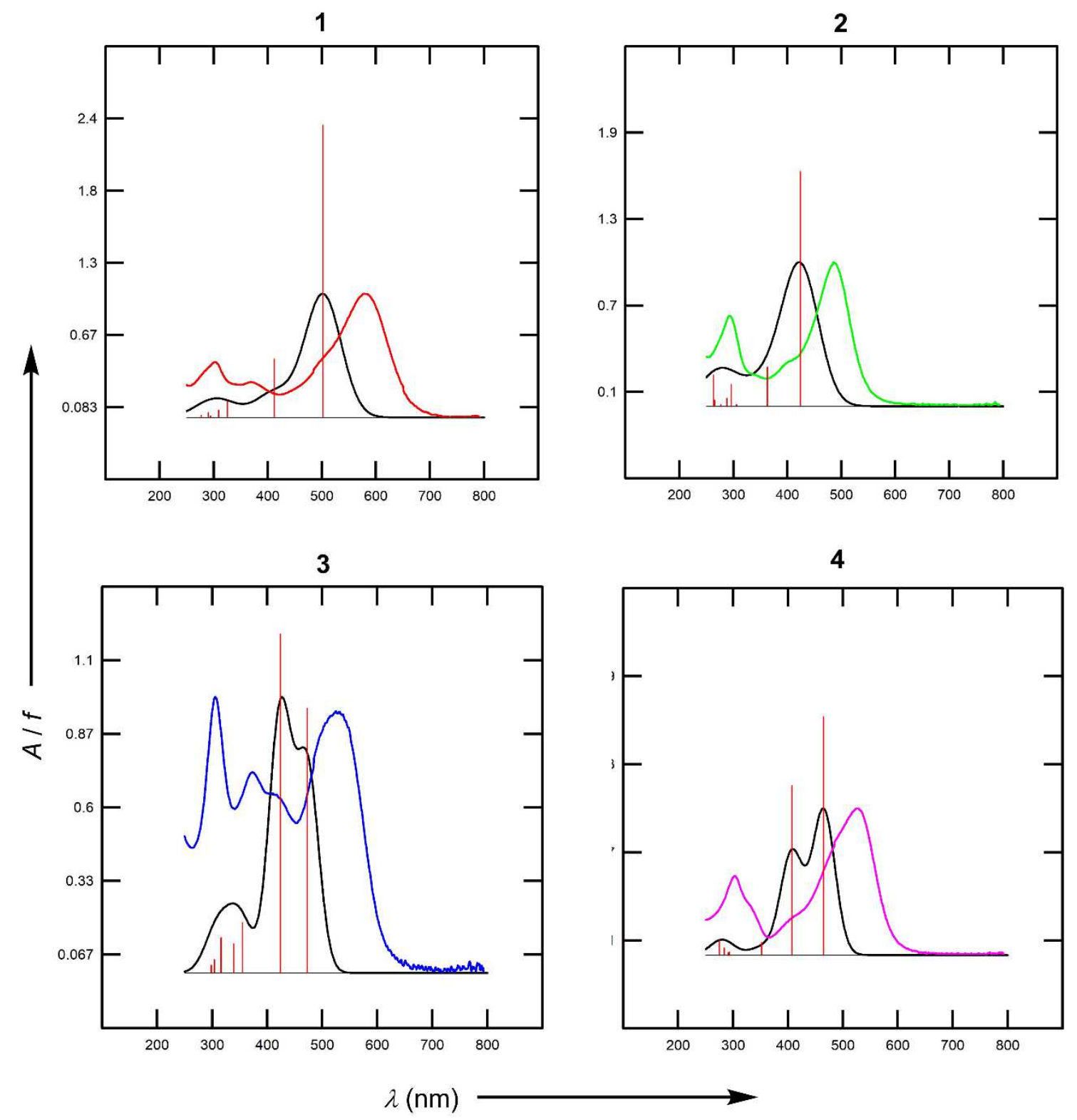

Figure S13: TD-DFT ( $\mathrm{n}$ states $=8$ ) CAM-B3LYP/6-311+G(2df,p) calculated UV-Vis spectra of chromophores 1-4 (black) along with the experimentally obtained spectra (in color) in $\mathrm{CHCl}_{3}$. Red vertical lines represent oscillator strengths $(f)$. 


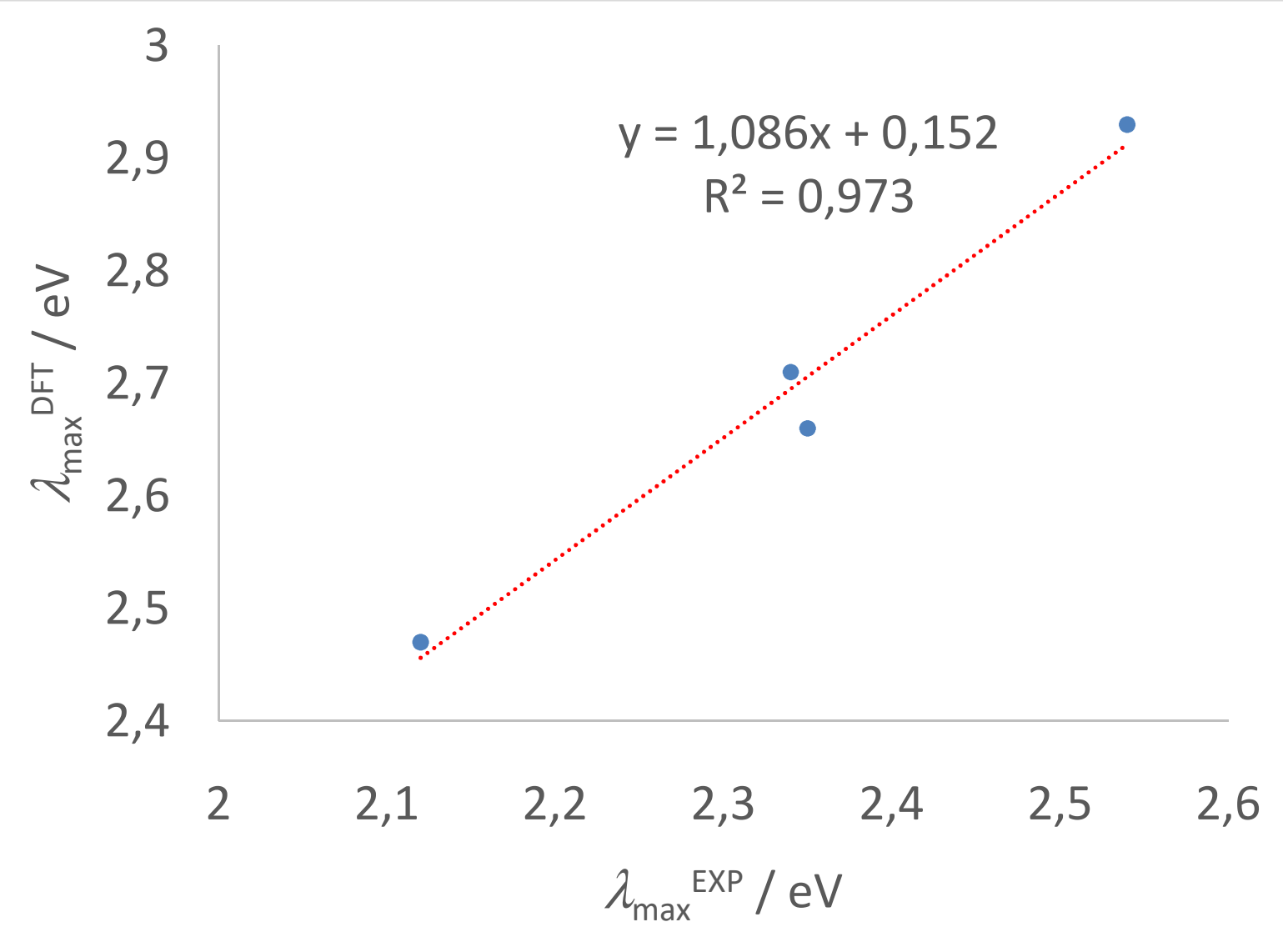

Figure S14: Correlation of TD-DFT calculated and experimental longest-wavelength absorption maxima $\lambda_{\max }$. 